\section{SYNLETT Spotlight 308}

This feature focuses on a reagent chosen by a postgraduate, highlighting the uses and preparation of the reagent in current research

\section{Trimethylsilyl Chloride (TMSCI)}

\section{Compiled by Yanchun Li}

Yanchun Li was born in Gansu, P. R. of China and received her B.Sc. degree (2007) in chemistry from the College of Longdong, Qingyang. She is currently pursuing her M.Sc. degree under the supervision of associate professor Dr. Zhengyin Du at the College of Chemistry and Chemical Engineering, Northwest Normal University in Lanzhou. Her research interests focus on the development of new synthetic methodologies for green chemistry.

College of Chemistry and Chemical Engineering, Northwest Normal University, 730070 Lanzhou, P. R. of China

E-mail: lychun123@126.com.cn

\section{Introduction}

Trimethylsilyl chloride is a valuable reagent in organic synthesis. It is a colorless liquid with a boiling point of $57-58^{\circ} \mathrm{C}$, easy to hydrolyse, unstable towards air, and has a pungent odor. It is commercially available and has been widely used in organic synthesis as chloridizing and activating reagents. Further it is used as protecting group and to accelerate and improve yields, stereospecificity, and regioselectivity for organic reactions. Herein, the applications of TMSCl in the recent five years are listed and reviewed.

\title{
Abstracts
}

(A) Lee and co-workers reported a novel and mild method for the 1,4 -addition of 1,3 -diesters to $\alpha, \beta$-unsaturated ketones using indium and $\mathrm{TMSCl}$ as the catalyst.

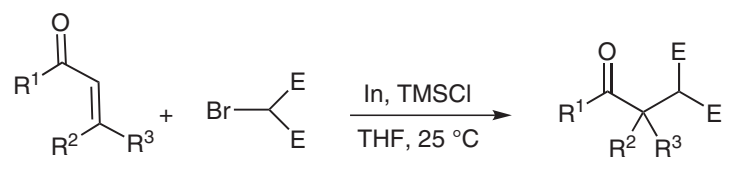

(B) Arylboronic acids undergo an ipso-nitration in the presence of chlorotrimethylsilane nitrate salts to give the corresponding nitroarenes in moderate to excellent yields. ${ }^{2}$

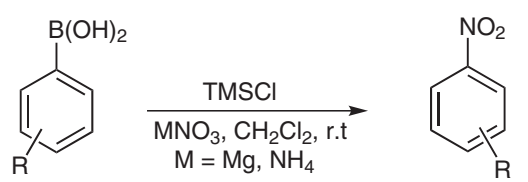

$20-98 \%$ yield

(C) Volochnyuk and co-workers reported a facile one-pot method for the synthesis of 2,3-dihydro- $1 H$-benzimidazoles using various ortho-dialkylaminoanilines and aldehydes or ketones in the presence of chlorotrimethylsilane. ${ }^{3}$<smiles>[R]CN(C[R])c1ccc([R])cc1N</smiles>

(D) In the presence of samarium and TMSCl diaryl dicyano ethenes gave the corresponding intramolecular cyclized indenes in good yields. However, the analogous alkyl aryl dicyano ethene afforded a dimeric product using the same conditions. ${ }^{4}$<smiles>N#CC(C#N)=C(c1ccccc1)c1ccccc1</smiles>

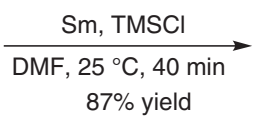<smiles>CS(=O)(=O)n1c(C#N)c(-c2ccccc2)c2ccccc21</smiles>

SYNLETT 2010, No. 5, pp 0837-0838

Advanced online publication: 24.02.2010

DOI: 10.1055/s-0029-1219345; Art ID: V31309ST

(c) Georg Thieme Verlag Stuttgart · New York 
(E) Thiols and disulfides could be directly converted into the corresponding sulfonyl chlorides in the presence of chlorotrimethylsilane nitrate salts in excellent yields through oxidative chlorination. Sulfides and sulfoxides were also found to undergo oxidation to sulfones under similar conditions. ${ }^{5}$

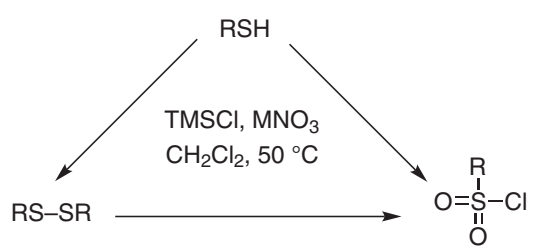

(F) A new multicomponent reaction of ortho-phthaldehyde, aldehydes, and $\mathrm{N}$-alkyl/aryl substituted ureas was developed in the presence of TMSCl. A series of novel 3-substituted isoindolinones were prepared for the first time in moderate yields with a diastereomeric excess of $>99 \% .^{6}$

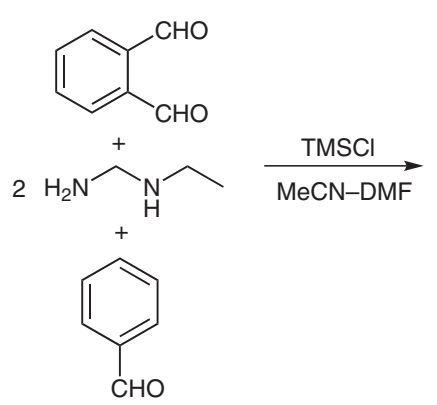

(G) A Mannich-type three-component reaction involving aldehydes, acetamide, and enolizable ketones or $\beta$-keto esters in the presence of TMSCl afforded $\beta$-acetamido carbonyl compounds with high diastereoselectivity. ${ }^{7}$

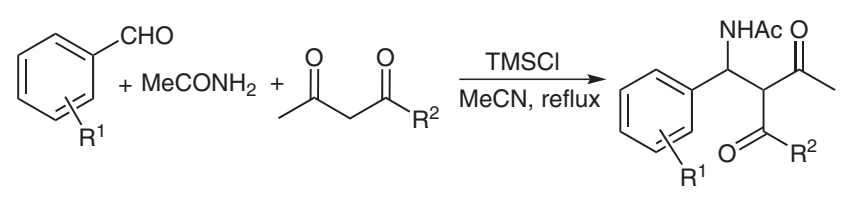

(H) A range of allylic alk-3(2)-enoates in the presence of DBU (1,8diazabicycl[5.4.0]undec-7-ene) and an excess amount of TMSCl under reflux in acetonitrile underwent an Ireland-Claisen [3,3] rearrangement to yield 2 -ethylidene $\gamma, \delta$-unsaturated carboxylic acids and 2-butenylidene $\gamma, \delta$-unsaturated carboxylic acids with high yields. ${ }^{8}$

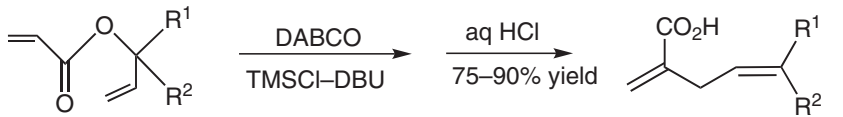

(I) Barnes et al. reported a facile and mild method for the synthesis of MOM-protected carbamates $(\mathrm{MOM}=$ methoxymethyl) in the presence of chlorotrimethylsilane, avoiding the use of carcinogen $\mathrm{MOM}-\mathrm{Cl}$. A variety of functionalities, including Boc, sulfonamide, and acetamide protecting groups are tolerant to this reaction. ${ }^{9}$

$\mathrm{R}^{1}=\mathrm{Ar}, \mathrm{Alk} ; \mathrm{R}^{2}=\mathrm{Bn}, \mathrm{Me}, t-\mathrm{Bu} ; \mathrm{R}^{3}=\mathrm{Me}, \mathrm{Et}, \mathrm{Bn}$

\section{References}

(1) Lee, P. H.; Seomoon, D.; Lee, K.; Heo, Y. J. Org. Chem. 2003, 68, 2510.

(2) Prakash, G. K. S.; Panja, C.; Mathew, T.; Surampudi, V.; Petasis, N. A.; Olah, G. A. Org. Lett. 2004, 6, 2205.

(3) Ryabukhin, S. V.; Plaskon, A. S.; Volochnyuk, D. M.; Shivanyuk, A. N.; Tolmachev, A. A. J. Org. Chem. 2007, 72, 7417.

(4) Liu, Y.; Zhao, Q.; Zhang, Y. Tetrahedron Lett. 2004, 45, 4571.
(5) Prakash, G. K. S.; Mathew, T.; Panja, C.; Olah, G. A. J. Org. Chem. 2007, 72, 5847.

(6) Wan, J. P.; Zhou, J.; Mao, H.; Pan, Y. J.; Wu, A. X. Tetrahedron 2008, 64, 11115.

(7) Mao, H.; Wan, J.; Pan, Y. Tetrahedron 2009, 65, 1026.

(8) Li, Y.; Goeke, A.; Wang, R.; Wang, Q.; Frater, G. Tetrahedron 2007, 63, 9605.

(9) Barnes, D. M.; Barkalow, J.; Plata, D. J. Org. Lett. 2009, 11, 273. 